\title{
PENGEMBANGAN MODEL PRAKTIKUM BERBASIS SOFTWARE MOST PROBABLE NUMBER (MP-BSMPN) PADA MATA KULIAH MIKROBIOLOGI AIR
}

\section{DEVELOPMENT OF PRACTICUM MODEL BASED ON SOFTWARE MOST PROBABLE NUMBER (MP-BSMPN) IN WATER MICROBIOLOGY COURSE}

\author{
Trisnawati, AAIA ${ }^{1)}$, Abdul Wahab Jufri ${ }^{2)}$, Agus Ramdani ${ }^{3)}$ \\ 1) Widyaiswara Muda Balai Pelatihan Kesehatan Mataram \\ ${ }^{2)}$ Megister Pendidikan IPA, Pascasarjana Universitas Mataram \\ Email: agungtrisnawati@yahoo.com
}

Diterima: 18 Agustus 2017. Disetujui: 05 September 2017. Dipublikasikan: 30 September 2017

\begin{abstract}
ABSTRAK. Tujuan penelitian ini adalah untuk mengetahui karakteristik, kelayakan, kepraktisan dan keterbacaan Model Praktikum Berbasis Software Most Probable Number (MP-BSMPN) pada mata kuliah Mikrobiologi Air. MP-BSMPN dikembangkan dengan prosedur pengembangan model Borg dan Gall. Produk yang dikembangkan adalah model praktikum yang pelaksanaannya menerapkan perangkat pembelajaran MP-BSMPN yang dikemas dalam 3 tahapan pelaksanaan yaitu: 1) Tahap persiapan praktikum, 2) Tahap pelaksanaan praktikum dan 3)Tahap akhir praktikum atau tindak lanjut praktikum. Hasil uji ahli menunjukkan bahwa kelayakan perangkat pembelajaran MP-BSMPN berkisar antara layak sampai sangat layak $(3,25-3,85)$. Tujuh perangkat mendapatkan nilai sangat layak, 2 perangkat bernilai layak. Perangkat MP-BSMPN yang mendapat nilai validasi ahli sangat layak adalah Rencana Pembelajaran Semester, Panduan Praktikum Mahasiswa dan Lembar Hasil Kerja Mahasiswa (PPM-LHKM), Instrumen Keterampilan Proses Sains dan Instrumen Penguasaan Konsep sedangkan Bahan Ajar Praktikum dan Media Pembelajaran Animasi MPN bernilai layak. Hasil uji empiris menunjukkan bahwa nilai tanggapan mahasiswa sebesar $77 \%$ dan pengajar $88 \%$ adalah praktis dan terbaca. Instrumen keterampilan proses sains dan penguasaan konsep terbukti valid dan reliabel (keterampilan proses sain $r=0,889$; penguasaan konsep $r=0,910$ ) dengan keterlaksanaan pembelajaran pada kategori terlaksana dengan sangat baik (92\%). Kesimpulan hasil penelitian adalah MP-BSMPN yang dikembangkan memiliki karakteristik perangkat pembelajaran yang sangat layak, praktis dan terbaca, terlaksana dengan sangat baik, valid dan reliabel serta dapat diterapkan dengan praktis sebagai model praktikum dalam pemeriksaan MPN Coliform dan Colitinja pada mata kuliah Mikrobiologi Air.
\end{abstract}

Kata Kunci: Model Praktikum Berbasis Software Most Probable, Mikrobiologi Air

\begin{abstract}
The purpose of this study was to determine the characteristics, feasibility, practicality and legibility Practical Model-Based Software Most Probable Number (MP-BSMPN) on Water Microbiology Course. MP-BSMPN model development procedure developed by Borg and Gall. The product developed is a practicum model whose implementation applies MP-BSMPN learning tool which is packed in 3 stages of implementation that is: 1) Practicum Preparation Stage, 2) Phase of Practicum Practicum and 3) Final Stage of Practicum or Practicum Follow Up. The test results indicate that the feasibility of expert learning device MP-BSMPN ranged from decent to very decent (3.25 to 3.85). Seven devices get very decent value, 2 devices are worth it. The MP-BSMPN tool that gets highly qualified expert validation is Semester Study Plan, Student Practicum Guide and Student Working Sheet (PPM-LHKM), Science Process Skill Instrument and Concept Mastery Instrument while Practicum Material and Media of MPN Animation Learning is worthy. The empirical test results show that the value of student responses by $77 \%$ and $88 \%$ is a practical teacher and legible. Instrument science process skills and mastery of concepts proved valid and reliable (science process skills $r=0.889$; mastery of concepts $r=0.91$ ) with keterlaksanaan learning in categories performing very well $(92 \%)$. Conclusion of the study is the MP-BSMPN developed has the characteristic learning device highly feasible, practical and legible, very successfully, valid and reliable and can be applied practically as a model practice in MPN Coliform and Colitinja examination in the subject of Microbiology Water.
\end{abstract}




\section{PENDAHULUAN}

Model pembelajaran praktikum merupakan salah satu pembelajaran berbasis kompetensi yang memiliki kedudukan amat penting dalam pembelajaran pada Diploma III Kesehatan. Pada model pembelajaran praktikum, peserta didik diberikan pengalaman belajar secara bersamaan antara kemampuan keterampilan, pengetahuan dan sikap ilmiah dengan menggunakan sarana laboratorium [1]. Praktikum yang terlaksana dengan baik secara serentak dapat meningkatkan hasil belajar peserta didik antara lain penguasaan konsep dan keterampilan proses sains [2]. Agar dapat meningkatkan hasil belajar peserta didik, praktikum harus dikemas dengan baik. Strategi penyampaian prosedur pemeriksaan dalam praktikum diharapkan menarik, kreatif dan inovatif sesuai dengan tingkat perkembangan kognitif peserta didik. Seorang pengajar atau dosen atau instruktur praktik harus dapat mengemas suatu pembelajaran praktikum yang menarik agar para peserta didik tertarik dan termotivasi. Dengan perkembangan teknologi dan informasi (TIK), suatu pembelajaran dapat menjadi lebih menarik yaitu dengan menggunakan pembelajaran berbantuan komputer.

Kenyataan di lapangan, secara umum hasil belajar dari penerapan metode praktikum terutama penguasaan konsep dan Keterampilan Proses Sains (KPS) mahasiswa yang rendah dapat disebabkan oleh kondisi pasif peserta didik karena jenis dan penyampaian materi yang kurang menarik. Sebanyak $85 \%$ mahasiswa menyatakan sulit memahami konsep-konsep abstrak pada materi praktik terutama kegiatan tahapan pemeriksaan dan perhitungan MPN Coliform dan Colitinja [3]. Metode ceramah klasikal membuat suasana kelas kurang menyenangkan. Mahasiswa tidak sepenuhnya dilibatkan, penggunaan sumber belajar hanya mengandalkan pedoman praktik laboratorium yang cenderung kurang menarik. Minimnya media pembelajaran yang dipakai mengakibatkan mahasiswa sulit mencerna konsep-konsep abstrak untuk diterjemahkan menjadi kemampuan dalam suatu pemeriksaan. Sebanyak $50 \%$ mahasiswa menyatakan perlu adanya pengembangan dari tabel Formula Thomas menjadi software yang aplikasi penggunaannya dalam bentuk offline agar mempermudah perhitungan.

Hasil wawancara dengan pengajar dan observasi awal di Prodi D III Kesehatan Lingkungan STTL Yayasan Mataram pembimbingan hanya berpedoman pada petunjuk praktikum laboratorium yang secara teknis tidak menjamin tercapainya tujuan pembelajaran. Proses pembelajaran praktik dilakukan tanpa adanya Rencana Pembelajaran Semester (RPS), Panduan Pelaksanaan Pembelajaran dan tidak adanya pedoman penilaian yang terstruktur. Penyampaian materi dengan metode ceramah dengan penayangan power point, petunjuk praktikum pemeriksaan bakteriologi air parameter MPN Coliform dan Colitinja yang kurang menarik sehingga mahasiswa sulit memahami konsep-konsep materi praktik yang bersifat abstrak. Permasalahan tersebut harus segera diselesaikan agar kualitas lulusan atau calon tenaga kesehatan yang dihasilkan dapat terjaga mutunya.

Pembelajaran praktikum berbantuan komputer melalui video eksperimen dan animasi dapat dipilih sebagai pertimbangan dalam pemecahan masalah peningkatan pemahaman konsep dan keterampilan proses sains [4-8]. Pemecahan masalah tersebut secara tidak langsung menyatakan bahwa diperlukan penerapan strategi pembelajaran yang sesuai disertai dengan media yang tepat dalam mengkonkretkan konsep abstrak yang akan dipelajari. Pengetahuan, sikap, dan keterampilan seorang pengajar sangat dibutuhkan dalam merancang pembelajaran terutama dalam praktikum laboratorium berbantuan komputer agar kualitas pembelajaran, pemahaman dan keterampilan konsep peserta didik meningkat dan sensitif terhadap perkembangan ilmu pengetahuan dan teknologi.

Berdasarkan latar belakang masalah dan alternatif pemecahan tersebut telah dilakukan penelitian Pengembangan Model Praktikum Berbasis Software Most Probable Number $(M P N)$ pada Mata Kuliah Mikrobiologi Air. Tujuan dari penelitian ini adalah untuk: 1) Mengetahui karakteristik Model Praktikum Berbasis Software Most Probable Number, 2) Mengetahui kelayakan perangkat Model Praktikum Berbasis dan 3) Mengetahui kepraktisan dan keterbacaan perangkat Model Praktikum Berbasis Software Most Software Most Probable Number).

\section{METODE PENELITIAN}

Penelitian ini termasuk penelitian pengembangan dengan pengembangan produk mengikuti prosedur pengembangan menurut Gall dan Borg yang telah dimodifikasi oleh Sukmadinata, dibatasi hanya sampai tahap pengembangan pada uji coba terbatas [9]. Perangkat pembelajaran yang dikembangkan antara lain Rencana Pembelajaran Semester (RPS), Bahan Ajar, Petunjuk Paktikum Mahasiswa-Lembar Hasil Kegiatan Mahasiswa (PPM-LHKM), media pembelajaran animasi MPN, Instrumen penelitian yang tediri dari Instrumen Keterampilan Proses Sains dan 
Penguasaan Konsep. Media pembelajaran Animasi MPN dikembangkan menggunakan program Macromedia adobe Flash 8 dikemas dalam bentuk $C D$.

Pengembangan MP-BSMPN dimulai dengan analisis awal dan pengembangan produk awal. Produk awal yang sudah dikembangkan selanjutnya secara berurutan dilakukan uji kelayakan produk (uji ahli), uji kepraktisan dan keterbacaan (uji perorangan), dan uji keterlaksanaan pembelajaran, validitas dan reliabilitas (uji kelompok kecil). Data penelitian diperoleh dari hasil validasi ahli materi diperoleh dengan memberikan produk perangkat pembelajaran dan software MPN dalam bentuk Compact Disk (CD) serta lembar validasi dalam bentuk lembar kuesioner dengan acuan skala likert serta instrumen penunjang berupa kuisioner respon tanggapan mahasiswa dan pengajar untuk setiap tahap uji coba. Subyek validasi adalah (1) uji ahli dengan 4 ahli pendidikan dari FKIP Universitas Mataram, (2) uji coba perorangan dengan 9 mahasiswa masing-masing 3 orang yang mewakili mahasiswa berkemampuan rendah, sedang dan tinggi yaitu 3 orang mahasiswa semester 6 Prodi D III Kesehatan Lingkungan STTL Yayasan Mataram dan 6 mahasiswa Prodi D III Farmasi Universitas Muhammadiyah Mataram (UMM), (3) uji coba kelompok kecil (17 mahasiswa semester II dari Prodi D III Kesling ), (4) uji coba lapangan terbatas (60 mahasiswa semester IV D III Farmasi UMM).

Rata-rata nilai validasi Ahli dengan kriteria penilaian kelayakan diadaptasi dari rata-rata skor, kriteria dan keputusan adalah; 1,00 - 1,75=Tidak layak (Belum dapat digunakan, memerlukan konsultasi); 1,76 - 2,51 Cukup layak=(Dapat digunakan dengan banyak revisi); 2,52 - 3,25= Layak (Dapat digunakan dengan sedikit revisi); 3,26 - 4,00 = Sangat layak (Dapat digunakan tanpa revisi) [8]. Kriteria Penilaian Kepraktisan dan Keterbacaan pengembangan perangkat MPBSMPN meliputi; $75-100 \%=$ praktis dan terbaca, dapat digunakan dengan sedikit revisi; 50 - $74 \%=$ Cukup praktis dan dapat terbaca, dapat digunakan dengan banyak revisi; $25-49 \%=$ Tidak praktis dan tidak terbaca, belum dapat digunakan, memerlukan konsultasi. Analisis validitas dan reliabilitas instrumen soal tes tertulis KPS dan penguasaan konsep menggunakan program Anatest versi 4.

\section{HASIL DAN PEMBAHASAN}

\section{Karakteristik MP-BSMPN yang \\ Dikembangkan}

Dalam penelitian ini telah dikembangkan suatu Model Praktikum Berbasis Software Most Probable Number (MP-BSMPN) berupa perangkat pembelajaran MP-BSMPN yang diterapkan pada 3 tahapan praktikum yaitu Tahap Persiapan Praktikum, Tahap Pelaksanaan Praktikum dan Tahap Akhir Praktikum atau Tahap Tindak Lanjut. Spesifikasi produk yang dikembangkan secara rinci disajikan pada Tabel 1 dan produk awal yang dikembangkan untuk setiap tahapan praktikum disajikan pada Tabel 2.

Tabel 1. Spesifikasi Model Praktikum Berbasis Software Most Probable Number (MP-BSMPN)

\section{No. Produk yang dikembangkan Uraian Isi}

$\begin{array}{ll}\text { A. Perangkat Pembelajaran } & \\ \text { 1. Rencana Pembelajaran } & \text { Matrik berupa tabel perencanaan pembelajaran yang } \\ \text { Semester (RPS) dan Panduan } & \text { memuat tentang Capaian Akhir Mata Kuliah, waktu } \\ \text { Pelaksanaan Pembelajaran (PPP) } & \begin{array}{l}\text { pelaksanaan, Kemampuan Akhir yang diharapkan, } \\ \text { indikator, pokok bahasan dan sub pokok bahasan, }\end{array} \\ & \text { metode pembelajaran, alokasi waktu dan referensi } \\ \text { dilengkapi dengan Panduan Pelaksanaan Pembelajaran } & \text { MP-BSMPN-BK }\end{array}$




\section{Bahan ajar}

3. Petunjuk Praktikum Mahasiswa dan Lembar Hasil Kerja Mahasiswa (PPM-LHKM)

\begin{abstract}
Sumber belajar yang terdiri dari 5 bab, Bab I Pendahuluan, Bab II,III,IV berisi materi secara berurutan adalah penyiapan alat dan bahan praktikum, pengambilan sampel air secara bakteriologis, dan pemeriksaan MPN Coliform dan Colitinja, Bab V Penutup, serta dilengkapi dengan soal latihan pada setiap akhir materi
\end{abstract}

PPM memuat tentang tata tertib, Standar Operasional Prosedur serta petunjuk praktikum pemeriksaan MPN Coliform dan Colitinja, terdiri dari 3 acara yang hasil penugasannya disajikan pada Lembar Hasil Kerja Mahasiswa (LHKM) yang juga terdiri dari 3 acara mengarah pada KPS terpadu meliputi merumuskan masalah, merumuskan hipotesis, merancang eksperimen, melakukan eksperimen, menginterpretasi data dan mengkomunikasikan hasil praktikum.

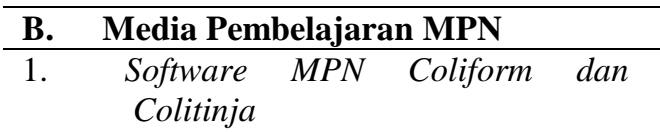

\section{C.Instrumen}

1. Instrumen tes tertulis Penguasaan Konsep

2. Instrumen Keterampilan Proses Sains ( KPS )
Berisi video animasi tahapan pemeriksaan $M P N$ Coliform dan Colitinja pada sampel air terdiri dari 2 ragam pemeriksaan 511 dan 555 yang dikemas dalam program Macromedia Flash 8, termasuk di dalamnya perhitungan menggunakan kalkulator Formula Thomas dalam program excel, penggunaan diakses secara offline dikemas dalam $C D$.

Instrumen tes tertulis yang memuat 25 pertanyaan pilihan ganda untuk mengukur penguasaan konsep, dikerjakan secara manual pada lembar jawaban yang disediakan.

- Instrumen tes tertulis yang memuat 10 soal tes tertulis berbentuk essay untuk mengukur KPS, dikerjakan secara manual pada lembar jawaban yang disediakan.

- Instrumen tes tidak tertulis berupa checklist Penilaian Kinerja KPS terpadu yang berisi poin-poin penilaian pada 6 aspek KPS, 2 aspek dinilai melalui observasi yaitu aspek pada saat pelaksanaan praktikum (merencanakan dan melakukan eksperimen), sedangkan 4 aspek lainnya dinilai berdasarkan penilaian jawaban dalam LHKM antara lain merumuskan masalah, menyusun hipotesis, menarik kesimpulan dan .mengkomunikasikan hasil berupa penyajian hasil praktikum dalam tabel.

- Instrumen penilaian presentasi hasil praktikum.

- Instrumen penilaian laporan hasil praktikum 
Tabel 2 Produk yang Dikembangkan dalam Model Praktikum Berbasis Software Most Probable Number (MP-BSMPN)

Tahapan Praktikum $\quad$ Produk yang dikembangkan

\begin{tabular}{|c|c|}
\hline Persiapan Praktikum & $\begin{array}{ll}\text { - } & \text { Tes tertulis Pre test mengukur KPS, PK } \\
\text { - } & \text { RPS, PPP MP-BSMPN, PPM-LHKM acara } 1 \\
\text { - } & \text { Bahan Ajar Praktikum MPN Coliform dan Colitinja } \\
\text { Bab II }\end{array}$ \\
\hline Pelaksanaan Praktikum & $\begin{array}{l}\text { - RPS, Bahan Ajar Praktikum Bab II dan III, PPP MP- } \\
\text { BSMPN-BK Praktikum penyiapan alat dan bahan, } \\
\text { praktikum pengambilan sampel air dan Pemeriksaan MPN } \\
\text { Coliform dan Colitinja } \\
\text { PPM-LHKM acara } 1 \text { streilisasi dan pembuatan media } \\
\text { media, acara } 2 \text { dan } 3 \text { yaitu Penyiapan Alat dan Bahan } \\
\text { Pemeriksaan, Pengambilan Sampel Air dan Pemeriksaan } \\
\text { MPN Coliform dan Colitinja } \\
\text { - Software MPN tentang Video animasi tahapan } \\
\text { Pemeriksaan MPN Coliform dan Colitinja yang dikemas } \\
\text { menjadi satu dengan Software Kalkulator Formula Thomas } \\
\text { dalam } C D \\
\text { Formulir Penilaian Kinerja KPS }\end{array}$ \\
\hline Akhir/Tindak Lanjut Praktikum & $\begin{array}{ll}\text { - } & \text { Formulir Penilaian Presentasi Hasil Praktikum } \\
\text { - } & \text { Formulir Penilaian Laporan Akhir Praktikum } \\
\text { - } & \text { Tes tertulis Post test mengukur KPS, PK }\end{array}$ \\
\hline
\end{tabular}

\section{Kelayakan Produk MP-BSMPN Dikembangkan}

\section{Uji Ahli}

Ahli pendidikan yang terdiri dari ahli materi dan ahli media telah melakukan penilaian kelayakan terhadap 9 komponen perangkat MP-BSMPN yang dikembangkan. Tujuh perangkat mendapatkan nilai sangat layak, 2 perangkat bernilai layak. Perangkat MP-BSMPN yang mendapat nilai validasi ahli sangat layak antara lain Rencana Pembelajaran Semester (RPS), (PPM-LHKM), Tes Tertulis Keterampilan Proses Sains (TT-KPS) dan Tes Tertulis Penguasaan Konsep (TT-PK), Tes Tidak Tertulis (Kinerja KPS, Presentasi Hasil Praktikum, Laporan Hasil Praktikum) sedangkan Bahan Ajar Praktikum (BA) dan media pembelajaran animasi MPN berupa Software MPN (SMPN) bernilai layak. Penilaian validasi ahli terhadap perangkat MP-BSMPN untuk setiap komponen disajikan pada Gambar 1.

Rentang nilai validasi berkisar antara 3,25 - 3,85 dengan kategori layak sampai sangat layak (Gambar 1). Bahan Ajar Praktikum merupakan perangkat MP-BSMPN yang mendapatkan nilai terendah sebesar 3,25 sedangkan Software MPN mendapatkan nilai tertinggi sebesar 3,85. Secara keseluruhan pencapaian perangkat MP-BSMPN kategori layak sampai sangat layak dengan keputusan dapat digunakan untuk tahap penelitian selanjutnya dengan melakukan beberapa perbaikan atau revisi.

Perolehan dalam kategori layak sampai sangat layak tesebut disebabkan karena menurut validator, RPS yang telah dikembangkan memenuhi persyaratan sebagai suatu perencanaan proses pembelajaran untuk mata kuliah Mikrobiologi Air dan telah memiliki spesifikasi lengkap sesuai dengan format standar RPS [11]. PPM-LHKM yang dikembangkan dinilai telah mampu mengakomodasi tercapainya Keterampilan Proses Sains dan penguasaan konsep secara konstruktif, peserta didik dilibatkan untuk membangun pengetahuannya sendiri secara aktif dengan menggunakan pengetahuannya yang telah dimiliki sebelumnya [12]. PPM-LHKM telah dikembangkan dari kumpulan langkah kerja menjadi lembaran kerja yang lebih efektif dan efisien tetapi tidak keluar dari konteks tercapainya kompetensi dasar dan tujuan pembelajaran yang diharapkan [13]. Materi pada bahan ajar dinilai memiliki keterkaitan antara Capaian Akhir Mata Kuliah dengan Kemampuan Akhir Yang Diharapkan, mengarah pada KPS dan penguasaan konsep mikrobiologi air, memiliki kebenaran isi materi karena mengacu pada sumber pustaka yang dapat dipertanggung jawabkan serta sesuai dengan perkembangan ilmu dan teknologi. Software MPN 
ini dianggap tepat dipadukan dengan metode praktikum serta telah memenuhi persyaratan sebagai media pembelajaran yang dapat memudahkan pengajar dalam menyampaikan konsep mikrobiologi air, terutama konsep abstrak menjadi konsep yang konkrit sehingga bisa dinalar mahasiswa [14].

\section{Uji Coba Terbatas}

Hasil dari uji coba skala kecil penilaian kepraktisan dan keterbacaan berdasarkan hasil uji empiris pada kelompok pengguna dari mahasiswa maupun pengajar adalah praktis dan terbaca. Mahasiswa dari 3 kemampuan yang berbeda menginginkan MP-BSMPN dapat diterapkan pada materi lainnya yang berbasis praktikum, mahasiswa lebih memilih desain pembelajaran multimedia model pembelajaran masa depan yang diinginkan dari pembelajaran berbantuan komputer dikenal dengan pembelajaran kombinasi antara tatap muka dan belajar mandiri [14].

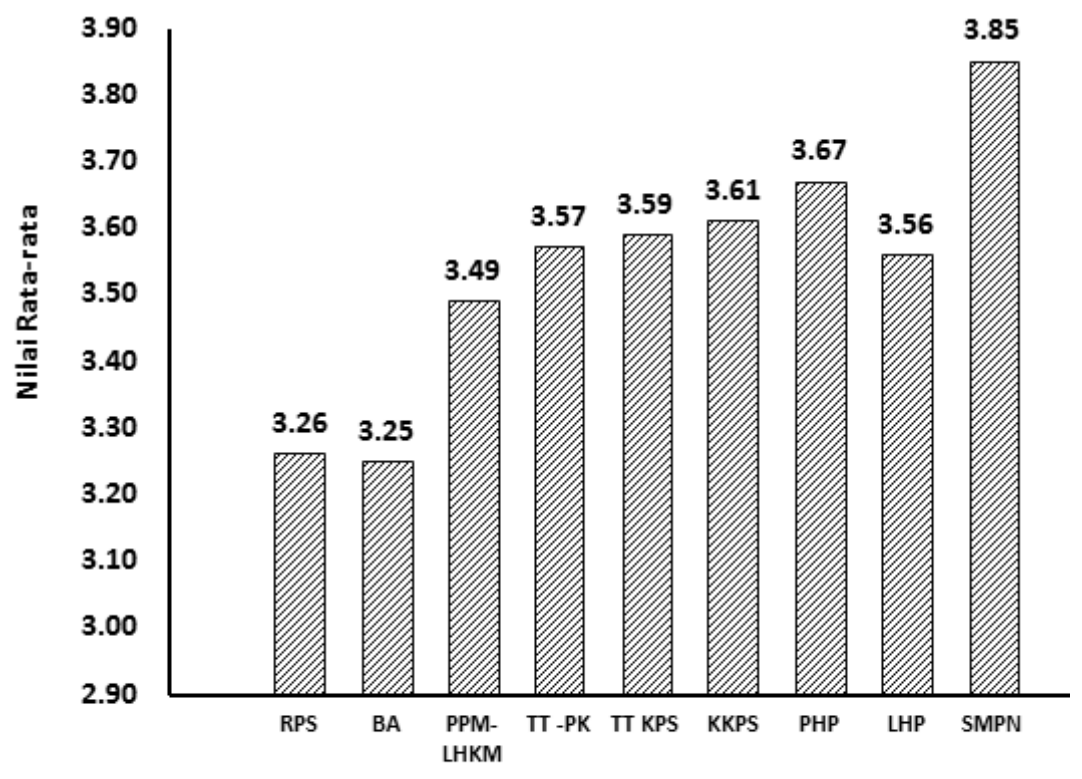

Perangakat Pembelajaran MP-BSMPN

Gambar 1. Penilaian Validasi Ahli Terhadap MP-BSMPN yang Telah Dikembangkan

Keterlaksanaan langkah-langkah pembelajaran pada uji kelompok kecil untuk Minggu I dan II sebesar $91 \%$ dan $95 \%$ dengan rata-rata $93 \%$ termasuk dalam kategori terlaksana dengan sangat baik. Nilai rata-rata terendah $70 \%$ dan 82 $\%$ pada tahapan inti yaitu pada pelaksanaan praktikum, pengajar tidak mencatat proses pelaksanaan diskusi kelompok dan praktikum. Penerapan langkah-langkah pembelajaran dengan MP-BSMPN mendapatkan tanggapan positip dari mahasiswa dengan kriteria sangat dapat diterapkan sebanyak $11(64,71 \%)$ dan dapat diterapkan sebanyak $6(35,29 \%)$, tanggapan positip dari pengajar dengan kriteria sangat dapat diterapkan $(91,7 \%)$.

Analisis validitas dan reliabilitas instrumen soal tes tertulis KPS dan penguasaan konsep menggunakan program Anatest versi 4. Tes tertulis Keterampilan Proses Sains dalam bentuk essay 10 butir soal (100\%) valid atau layak digunakan dengan tingkat kesukaran dari 10 soal tes tertulis keterampilan proses sains sebesar 1(10 $\%)$ sukar, 9 (90\%) sedang, 0 (0\%) mudah. Hasil analisis reliabilitas tes tertulis KPS reliabel pada taraf signifikansi $5 \%$, nilai $r 0,889>\mathrm{r}$ kritis product moment 0,482. Hasil analisis dari 25 tes tertulis penguasan konsep bentuk pilihan ganda, $22(88 \%)$ butir soal valid atau layak dan digunakan sedangkan 3 (12\%) tidak valid/layak. Hasil analisis reliabilitas tes tertulis penguasaan konsep berupa pilihan ganda adalah reliabel pada taraf signifikansi $5 \%$ nilai $r$ 0,91 > r kritis product moment 0,482. Berdasarkan hasil reliabilitas, validitas dan tingkat kesukaran soal, untuk uji lapangan skala terbatas, peneliti memutuskan menggunakan 20 butir soal pilihan ganda penguasaan konsep dan 10 soal essay untuk tes tertulis KPS. Berdasarkan hasil uji coba kelompok kecil, keterlaksanaan pembelajaran menggunakan MP-BSMPN telah tercapai dengan rata-rata penilaian keterlaksanaan $\geq 61 \%$ yaitu terlaksana dengan sangat baik, instrument valid dan reliabel maka MP-BSMPN yang dikembangkan layak digunakan sebagai metode pembelajaran alternatif yang inovatif, menarik sesuai dengan perkembangan ilmu pengetahuan dan teknologi serta layak untuk dipergunakan pada tahap penelitian selanjutnya yaitu 
implementasi pada uji lapangan terbatas atau uji lapangan skala luas.

\section{KESIMPULAN DAN SARAN \\ Kesimpulan}

Berdasarkan uraian diatas, dapat disimpulkan bahwa MP-BSMPN yang dikembangkan memiliki karakteristik dengan perangkat pembelajaran yang sangat layak, praktis dan terbaca, terlaksana dengan sangat baik, valid dan reliabel serta dapat diterapkan dengan praktis sebagai model praktikum dalam pemeriksaan MPN Coliform dan Colitinja pada mata kuliah Mikrobiologi Air.

\section{Saran}

Pengajar/Dosen/Instruktur Praktik dapat menerapkan MP-BSMPN dalam pembelajaran Mikrobiologi Air agar proses pembelajaran menarik, mudah dipahami oleh mahasiswa dan sesuai dengan perkembangan ilmu pengetahuan dan teknologi. Mahasiswa hendaknya menyiapkan komputer terinstal program microsoft word 2010 agar bisa mengakses MPN Kalkulator Formula Thomas yang ada pada animasi MPN. Lembaga/Institusi Pendidikan mengupayakan pemenuhan sarana prasarana praktik sehingga penerapan MP-BSMPN tidak hanya dilakukan di dalam kelas tetapi juga pada ruang laboratorium. Peneliti selanjutnya. melakukan pengembangan produk pada wilayah yang lebih luas.

\section{DAFTAR PUSTAKA}

[1] Tim Kurikulum dan Pembelajaran Direktorat Pembelajaran dan Kemahasiswaan. 2014. Buku Kurikulum Pendidikan Tinggi. Jakarta: Direktorat Jenderal Pendidikan Tinggi Kementerian Pendidikan dan Kebudayaan.

[2] Surachman, M., Muntari, M., \& Savalas, L. R. T. 2014. Pengembangan Multimedia Interaktif Berbasis Kontekstual untuk Meningkatkan Penguasaan Konsep dan Keterampilan Berpikir Kritis Siswa Kelas XI Pada Materi Pokok Sistem Koloid. Jurnal Pijar MIPA, 9(2).

[3] Trisnawati, AAIA. 2015. Kajian Awal Pengembangan Metode dan Alat bantu Pembelajaran dalam Pengujian MPN Coliform dan Colitinja Pada Mata Kuliah Mikrobiologi Lingkungan Prodi Kesehatan Lingkungan STTL Mataram Tahun 2015. Jurnal Sangkareang Mataram, 1(3): 8-13.

[4] Haryono. 2006. Model Pembelajaran Berbasis Peningkatan Keterampilan Proses Sains. Jurnal Pendidikan Dasar. 7(1): 1-13.
[5] Sari, D dan Tarigan, S. 2014. Pengaruh Model Pembelajaran Berbasis Masalah Berbantuan Komputer Terhadap Hasil Belajar Peserta didik Pada Materi Pokok Cahaya Kelas VIII SMP Negeri 11 Medan. Jurnal Inpafi vol.2(3):63-72.

[6] Adnyana, P.G. 2013. Video Eksperiment dan Animasi untuk Meningkatkan Pemahaman Konsep Kimia. Jurnal Pendidikan Pendidikan dan Pengajaran 46(3):268-277.

[7] Taufiq, M. 2008. Pembuatan Media Pembelajaran Berbasis Compact Disc Untuk Menampilkan Simulasi Dan Virtual Labs Besaran-Besaran Fisika. Jurnal Pijar MIPA, 3(3), 68-72.

[8] Wahyuningsih, W., Jamaluddin, J., \& Karnan, K. (2015). Penerapan pembelajaran Biologi berbasis macromedia flash dan implikasinya terhadap keterampilan metakognitif dan penguasaan konsep siswa kelas VIII SMPN 6 Mataram. Jurnal Pijar MIPA, 10(1).

[9] Sukmadinata, N.S. 2016. Metode Penelitian Pendidikan. Bandung: PT. Remaja Rosdakarya.

[10] Ratumanan, T. G., dan Laurens, T. (2011). Penilaian Hasil Belajar pada Tingkat Satuan Pendidikan Edisi 2. Surabaya: Unesa University Press.

[11] Peraturan Menteri Riset, Teknologi, dan Pendidikan Tinggi Republik Indonesia Nomor 44 Tahun 2015 tentang Standar Nasional Pendidikan Tinggi

[12] Jufri, W. 2013. Belajar Dan Pembelajaran Sains. Bandung: Pustaka Reka Cipta.

[13] Rachmad, YTB, Susantini dan Ambarwati R. 2015. Validitas Lembar Kegiatan Siswa (LKS) Pengamatan Pada Materi Filum Molusca Kelas X SMA. BioEdu, 4(2): 913917

[14] Hermansyah, H., Gunawan, G., \& Herayanti, L. 2017. Pengaruh penggunaan laboratorium virtual terhadap penguasaan konsep dan kemampuan berpikir kreatif siswa pada materi getaran dan gelombang. Jurnal Pendidikan Fisika dan Teknologi, 1(2), 97102. 